\title{
Meu nome era Sabina Spielrein. Eu fui também psicanalista
}

\author{
My name was Sabina Spielrein. \\ I was also a psychoanalyst \\ Mi nombre era Sabina Spielrein. \\ Yo también fui una psicoanalista
}

\author{
Paula Regina Peron* \\ Flávia Ripoli Martins ${ }^{* *}$
}

\section{Resumo}

O presente trabalho resgata a importância de Sabina Spielrein, uma das primeiras mulheres da história da psicanálise, recordando sua trajetória biográfica e proposições sobre o conceito de pulsão de morte, e examinando contribuições à compreensão freudiana relativa a esse conceito. As principais referências foram textos de Spielrein e de Freud e documentos históricos, como as cartas trocadas entre Freud, Jung e Spielrein, o diário pessoal da autora e as "Atas da Sociedade Psicanalítica de Viena". Percebemos que há entre Freud e Spielrein uma trajetória de questões semelhantes acerca da psicose, que fomenta o estudo da pulsão de morte. O artigo assinala que ambos valeram-se do pensamento biológico para suas proposições e que apresentam considerações semelhantes sobre o sadismo e o masoquismo. Quanto à pulsão de morte, para Freud trata-se de pulsão que objetiva a redução absoluta das tensões, conduzindo o ser vivo de volta ao estado inorgânico pela via do desligamento e da destruição. Para Spielrein, a pulsão de morte está oculta na pulsão sexual e, apesar de visar à destruição, objetiva a transformação, morte para o antigo e vida para o que vai surgir.

Palavras chaves: Sabina Spielrein, Freud, pulsão de morte

Pontifícia Universidade Católica de São Paulo. Faculdade de Ciências Humanas e da Saúde. Departamento de Psicodinâmica. E-mail: prperon@uol.com.br

** Pós-graduanda em psicologia clínica pela PUC SP. E-mail: flaviamripoli@gmail.com 


\section{Abstract}

The present work highlights the importance of Sabina Spielrein, one of the first women to become a psychoanalyst. It examines her trajectory and propositions on the concept of death drive, in relation to Freud's propositions. The main references were the texts of Spielrein and Freud, and historical documents, such as the letters between Freud, Jung and Spielrein, Spielrein's personal diary and the Minutes of the Vienna Psychoanalytic Society. There is an exchange of similar questions about psychosis between Freud and Spielrein, which encourages them to study the death drive. The article points out that both used a biological basis for their arguments and that they present similar considerations on sadism and masochism. As for the death instinct, Freud considers it as a drive that aims at the absolute reduction of tensions, leading the living being back to the inorganic state by means of detachment and destruction. For Spielrein, the death instinct is hidden in the sexual drive and, despite aiming at destruction, also aims at transformation.

Keywords: Sabina Spielrein, Freud, death instinct

\section{Resumen}

El presente trabajo destaca la importancia de Sabrina Spielrein, una de las primeras mujeres de la historia del psicoanálisis, presentando su trayectoria biográfica y proposiciones sobre el concepto de pulsión de muerte, examinando contribuciones a la comprensión freudiana relativa a ese concepto. Las principales referencias fueron los textos de Spielrein, de Freud, y documentos históricos. como las cartas intercambiadas entre Freud, Jung y Spielrein, el diario de la autora y "las Actas de la Sociedad Psicoanalítica de Viena". Percibimos que entre Freud y Spielrein hay una trayectoria semejante en relación a las cuestiones acerca de la psicosis, que fomentan el estudio de la pulsión de muerte. El artículo señala que ambos se valieron de pensamientos biológicos para sus proposiciones y que presentan consideraciones semejantes sobre el sadismo y el masoquismo. En cuanto a la pulsión de muerte, para Freud se trata de una pulsión que objetiva la reducción absoluta de las tensiones, conduciendo al ser vivo de vuelta al estado inorgánico por la vía del desprendimiento y la destrucción. Para Spielrein, la pulsión de muerte está oculta en la pulsión sexual $y$, a pesar de visar la destrucción, objetiva la transformación, muerte para lo antiguo y vida para lo que va a surgir.

Palabras clave: Sabina Spielrein, Freud, pulsión de muerte

Últimos desejos. Quando eu morrer [...] o corpo deve ser cremado, guém deve estar presente. As cinzas devem ser divididas em três partes. Uma parte deve ser colocada em uma urna e enviada para casa; a segunda deve ser espalhada na terra, no meio de um imenso campo (perto de casa); 
lá deve ser plantado um carvalho com a inscrição: "Eu também fui um ser humano. Meu nome era Sabina Spielrein" (Spielrein, 1904, como citado em Richenbächer, 2012, p. 335). ${ }^{1}$

Considerado um dos pilares fundamentais da Psicanálise freudiana, o conceito de pulsão de morte é uma teorização de imensa repercussão, tanto por seus efeitos no pensamento filosófico do século XX, quanto pelas polêmicas e rejeições que provocou entre os seguidores de Freud (Roudinesco \& Plon, 1998), dando lugar a diversas interpretações e controvérsias ainda hoje (Widlöcher, 1988).

Se as questões acerca deste conceito parecem ter origem em Além do princípio do prazer (Freud, 1920), um estudo aprofundado evidencia que foram sendo paulatinamente construídas. Freud aponta para suas resistências ao afirmar: "recordo a minha própria atitude defensiva, quando a ideia do instinto ${ }^{2}$ de destruição surgiu pela primeira vez na literatura psicanalítica, e quanto tempo durou até que eu me tornasse receptivo a ela" (Freud, 1930, p. 87). Concebendo que o pensamento freudiano surge de "campos de nexos e rupturas que transcendem uma noção muito estrita de 'obra' ou 'autoria"' (Figueiredo, 1999, p. 126), compreender a quais autores ele se referia nesta citação tornou-se o primeiro eixo para a criação deste trabalho.

Foi por meio da leitura da biografia Freud: uma vida para nosso tempo que começamos a elucidar esta questão. $\mathrm{O}$ autor afirma que:

Um pouco pesaroso, ele evocou sua própria atitude defensiva de tal pulsão, quando a ideia surgiu pela primeira vez na literatura psicanalítica, e "o quanto demorou até que eu me tornasse receptivo a ela”. Freud estava pensando numa apresentação da brilhante analista russa Sabina Spielrein, nos dias pioneiros de 1911, numa das reuniões das quartas-feiras à noite, na

1 Poema escrito por Sabina Spielrein no outono de 1904, quando estava internada no hospital Burghölzli e escreveu em seu diário textos sobre a morte, a solidão e o sofrimento.

2 As Obras Completas de Freud da editora Companhia das Letras e a Edição Standard Brasileira das Obras Psicológicas Completas de Sigmund Freud da editora Imago traduziram as concepções freudianas de Trieb e Instinkt pelo termo instinto, o que pode gerar indistinções entre os conceitos (Laplanche \& Pontalis, 2001). O presente trabalho utilizará o termo pulsão ao se referir ao conceito de Trieb. Em citações literais das obras de Freud, respeitaremos a tradução do editor. 
Berggasse 19, e também no artigo pioneiro dela, no ano seguinte, intitulado “A destruição como causa do vir-a-ser”. Naqueles anos, Freud simplesmente não estava preparado (Gay, 2012, p. 402).

Fomos então levadas a pesquisar sobre Sabina Spielrein, cuja história gera fascínio e polêmicas. Ela foi retratada em produções cinematográficas sobre a história da Psicanálise (Jornada da alma [Franza \& Ferri, 2002] e Um método perigoso [Cronenberg \& Thomas, 2011]), como histérica ou psicótica, e seu romance com Jung predomina nas menções ao seu nome. Poucos sabem que Sabina Spielrein tornou-se uma brilhante autora e analista, tendo sido a segunda mulher a integrar a Sociedade Psicanalítica de Viena e sendo considerada uma das pioneiras autoras do movimento psicanalítico (Alonso, 2014), com importantes contribuições teórico-clinicas.

Analisando este contraste, Cromberg (2008, p. 307) considera que o "soterramento histórico da obra" de Spielrein é resultado de diversos fatores, como o fato dela ter sido mulher, judia, russa, e de ter estado entre as desavenças de Jung e Freud. Enfrentou o stalinismo, o nazismo e a misoginia dentro e fora do movimento psicanalítico, fenômenos determinantes para que "essa psicanalista russa, [fosse] esquecida pela historiografia oficial" (Roudinesco \& Plon, 1998, p. 725) até 1980, quando foi finalmente retomada. Como exemplo, a densa biografia brasileira de Sigmund Freud, escrita por Emilio Rodrigue (1995), já a menciona, não apenas como amante de Jung, mas em sua influência na teorização da pulsão de morte.

Ela foi redescoberta quando seu diário, textos publicados entre 1911 e 1923, e correspondências entre Spielrein, Jung e Freud foram encontrados nos porões do local que sediava o Instituto de Psicologia de Genebra, culminando na publicação do primeiro trabalho sobre Spielrein, intitulado Diário de uma secreta simetria (Carotenuto, 1984). Iniciou-se um movimento que Alonso (2014) denomina "a construção em processo" da biografia de Spielrein.

Afinal, se a autora é indiretamente evocada por Freud na passagem previamente citada de O Mal-estar na civilização (Gay, 2012), deve-se 
perguntar qual a relação entre o que ela propõe em $A$ destruição como origem do devir (Spielrein, 1912) e a formulação freudiana da pulsão de morte.

Mencionada apenas no rodapé dos textos freudianos, a relação entre a autoria de Spielrein e Freud foi levantada por Jung. Ao citar uma passagem de Esboço de Psicanálise, onde Freud (1939) discute a pulsão de morte, Jung menciona que "esta ideia é de autoria de minha aluna Dra. S. Spielrein” (Jung, 1942, p. 40,§ 33) remetendo à publicação de $A$ destruição como origem do devir (Spielrein, 1912).

Alguns autores como Alonso (2014), Endo (2015) e Brome (1967) afirmam que $A$ destruição como origem do devir (Spielrein, 1912) antecipa o conceito de pulsão de morte de 1920. Robert (1966) chega a dizer que o artigo antecipa-o quase ponto a ponto. Mas não há unanimidade quanto a estas relações. Alguns defendem que ela foi a "visionária introdutora do conceito de pulsão de morte em psicanálise” (Cromberg, 2014, p. 91), e outros afirmam que "uma análise atenta do texto de Spielrein revela que há diferenças fundamentais que distanciam a sua hipótese daquela de Freud" (Caropreso, 2016, p. 414).

Instigadas, restaram-nos as questões: predominam semelhanças ou discrepâncias entre as obras citadas? O texto A destruição como origem do devir (Spielrein, 1912) pode auxiliar no entendimento da pulsão de morte? E por que raramente ouvimos falar das produções de Sabina Spielrein, participante do movimento psicanalítico antes de outras discípulas de Freud mais conhecidas, como Melanie Klein e Anna Freud? Em um momento de debates sobre as relações entre a Psicanálise e as questões sobre o feminino, acreditamos na relevância de estudar a vida e obra das primeiras psicanalistas, especialmente as menos conhecidas no Brasil. Antes de buscar entender como a teorização da autora pode contribuir à compreensão do segundo dualismo pulsional freudiano, destacaremos passagens biográficas de Sabina Spielrein. Entretanto, alertamos que se trata de considerações abreviadas pela extensão do presente texto, cabendo-nos salientar apenas alguns pontos importantes relativos às densas questões acima apresentadas. 


\section{BREVE BIOGRAFIA DE SPIELREIN}

Sabina Spielrein compôs, juntamente com Emma Eckstein, Margarethe Hilferding, Hermine von Hug-Hellmuth, e Tatiana Rosenthal, a primeira geração de mulheres psicanalistas. Tiveram seus destinos marcados pela violência e pelo adoecimento psíquico, condições comuns às mulheres burguesas do início do século XX, cujo sofrimento muitas vezes exprimia um protesto contra sua condição social. Suas proposições teóricas muitas vezes foram preteridas e seus nomes passaram a ser reconhecidos somente a partir da década de 60, com o surgimento de uma crítica ao saber clássico, caracterizada por ser a construção de uma "história das mulheres" (Roudinesco, 2009, p. 86).

Nascida em Rostov, na Rússia, educada para o trabalho e estudos e, conforme expresso em seus diários, negando identificar-se à posição materna, que remetia ao casamento e à maternidade, Spielrein adoeceu quando, em sua condição de mulher e judia, não conseguiu encontrar um lugar para continuar seus estudos (Richebächer, 2012). Seu desejo de investir em uma carreira intelectual e tornar-se independente foi barrado e assim não encontrou possibilidades sublimatórias, colaborando para um quadro psicológico grave, que levou Sabina a ser internada em Burghölzli ${ }^{3}$ entre 17 de Agosto de 1904 e $1^{\circ}$ de Junho de 1905.

Spielrein encontrou pioneiros, dentre eles Jung e Bleuler, que demonstravam grande interesse pela Psicanálise. Sob a responsabilidade de Jung, seu caso foi o primeiro no qual ele pôde aplicar o método freudiano, com autorização de Bleuler, que já trocava correspondências com Freud (Richebächer, 2012). Jung afirma sobre o tratamento de Sabina: "foi, por assim dizer, meu caso-teste" (McGuire, 1993, p. 279).

Curada de seus principais sintomas, Spielrein iniciou seus estudos na Escola de Medicina de Zurique, graduando-se em 1911 e apresentando como tese de dissertação a obra Sobre o conteúdo psicológico de um caso

3 Localizado em Zurique, inaugurado em 1870, o hospital Burghölzli encontrava-se, quando Sabina Spielrein foi internada, sob direção de Bleuler. A instituição caracterizava-se por ser um lugar de estudo e aplicação de tratamentos pioneiros, entre os quais a Psicanálise (Richebächer, 2012). 
de esquizofrenia (Spielrein, 1911), publicada no Jahrbuch. ${ }^{4}$ Ela "é a primeira mulher da história a se formar como doutora em medicina abordando um tema psicanalítico [realizando também] um dos primeiros usos públicos do termo cunhado por Bleuler (esquizofrenia)" (Cromberg, 2014, p. 37).

Assim, Spielrein conheceu um lugar de acolhida onde podia pesquisar, trabalhar e publicar. No ano de 1912, encontrou-se com Freud, passando a frequentar as reuniões da Sociedade Psicanalítica de Viena (Roudinesco, 2009). Aceita como membra da Sociedade em 11 de Outubro de 1911, ela tornou-se a segunda mulher a ser integrada ao circulo freudiano, e a única até fevereiro de 1912, quando ocorreu a nomeação de Tatiana Rosenthal, já que Margarethe Hilferding renunciou na mesma data da entrada de Sabina, integrando o grupo de discípulos que seguiu Adler em sua ruptura com Freud (Nunberg \& Federn, 1979; Roudinesco, 2009).

Sabina apresentou à Sociedade uma parte do extenso trabalho $A$ destruição como origem do devir (Spielrein, 1912), no qual introduz o conceito de pulsão de morte, vivendo um período onde "consegue muitas conquistas profissionais: é membro da Sociedade Psicanalítica, trabalha com sucesso como analista e seu novo artigo deve ser publicado no Anuário [Jahrbuch] no verão" (Richebächer, 2012, p. 181). Freud pede a ela que seus escritos sejam publicados com exclusividade por revistas da Associação Psicanalítica Internacional, e entre 1912 e 1914, Sabina publicou ao todo onze trabalhos (Cromberg, 2014).

Após aproximadamente dois anos de elaboração da escrita, em setembro de 1912 publicou A destruição como origem do devir, no Jahrbuch, logo depois da segunda parte do trabalho de Jung denominado Símbolos da transformação, que já apontava para a ruptura definitiva entre ele e Freud, no ano de 1913 (Gay, 2012). Fiel a Freud do ponto de vista científico, mas não pronta para romper pessoalmente com Jung, Sabina manteve uma posição ambígua em meio ao conflito que protagonizavam. Em Berlim, na Sociedade de Psicanálise presidida por Abraham, sua atitude não foi bem aceita. Além das divergências pessoais entre Sabina e Abraham,

4 "Criado em 1909 por iniciativa de Freud e Bleuler, o Jahrbuch [Anais de pesquisas psicanalíticas e psicopatológicas] foi a primeira revista do movimento psicanalítico [...]. Deixou de existir em 1913” (Roudinesco \& Plon, 1998, p.407). 
fruto principalmente das relações entre ele e Jung, o grupo berlinense era bastante resistente à entrada de mulheres, ao contrário do grupo de Zurique, para onde ela e Pavel Scheftel, com quem se casara e tivera uma filha, decidem se mudar (Cromberg, 2014; Roudinesco, 2016).

Com o início da Primeira Guerra em 1914, Pavel é convocado para lutar na Rússia e Sabina permanece na Suíça, um terreno neutro. Entre 1915 e 1917 publica Uma sentença inconsciente e As manifestações do complexo de Édipo na idade infantil, na Revista Internacional de Psicanálise Médica. Em setembro de 1920, viajou para participar do VI Congresso Internacional de Psicanálise em Haia, onde apresentou "O surgimento e o desenvolvimento da fala articulada”.

Após o término do congresso, Sabina muda-se para Genebra, para trabalhar no Instituto Jean-Jacques Rousseau, aproximando seus trabalhos da área da pedagogia e do desenvolvimento infantil. Entre 1920 e 1921 viveu um período bastante produtivo, publicando seis artigos sobre a análise infantil e ministrando um curso sobre Psicanálise e Pedagogia no Instituto. Ela tornou-se analista de Jean Piaget, com quem desenvolveu trabalho sobre as origens da linguagem e do pensamento nas crianças (Cromberg, 2014).

Em 1923, pressionada por Pavel e parentes para retornar para seu país e apoiada por Freud, Spielrein muda-se para a Rússia, onde o movimento psicanalítico estava em seu apogeu. Vivendo em Moscou e sendo considerada "a psicanalista com a melhor formação na URSS" em função de seu longo trajeto (Cromberg, 2017, p. 117), Sabina trabalhou no Instituto Estatal de Psicanálise e no Lar Experimental para Crianças, atuou como consultora médico-pedagógica da Terceira Internacional, foi diretora do Departamento de Psicologia Infantil da Primeira Universidade de Moscou, e voltou a lecionar Psicanálise. Na primavera de 1924, retornou para Rostov onde continuou exercendo a Psicanálise e a Pedologia e em 1931 publicou seu último trabalho: Desenhos infantis feitos com olhos abertos e fechados.

A Psicanálise na URSS era uma disciplina apoiada pelo Estado, deixando-a excessivamente suscetível às mudanças políticas. Com a ascensão de Stálin em 1927, o movimento psicanalítico russo foi levado a uma progressiva dissolução, embora muitos analistas praticassem na clandestinidade (Cromberg, 2017). 
Sabina passa a sobreviver com um trabalho de médica em uma escola, praticando a Psicanálise ilegalmente, e vivendo sozinha com suas filhas. A situação torna-se mais hostil no momento em que Hitler invade a União Soviética, e Rostov é invadida e conquistada, culminando em 1942 no extermínio da população judaica (Richebächer, 2012).

Segundo Richebächer (2012), formulários do Memorial Yad Vaschem em Jerusalém atestam a morte de Sabina e suas filhas durante o extermínio em Rostov. Não se sabe ao certo data ou circunstância de suas mortes, sobre quais são apresentadas versões cujos detalhes são pouco relevantes diante da violência dos fatos:

Tantas versões, tantas repetições de um chocante fim trágico, trauma que pede elaboração, inelaborável, como se ao escrever várias versões de sua morte pudéssemos esconjurar o horror de uma destruição que ela sempre quis que fosse a causa do devir, mas que, no seu próprio fim, foi aquilo que Freud dissera: o puro mal, a fúria narcísica onipotente, o puro prazer de humilhar, maltratar e destruir. Sem devir (Cromberg, 2014, p. 55).

\section{PULSÃO DE MORTE: FREUD E SPIELREIN}

Examinaremos resumidamente agora a formulação de Freud sobre a pulsão de morte, que surgirá como conceito em 1920, com a publicação de Além do princípio do prazer. Considerado um dos pilares fundamentais da teoria freudiana, a pulsão pode ser definida, de acordo com o que é colocado por Freud no ensaio $O$ instinto e seus destinos:

como um conceito-limite entre o psíquico e o somático, como representante psíquico dos estímulos que provêm do interior do corpo e alcançam a psique, como uma medida de exigência de trabalho imposta ao psíquico em consequência de sua ligação com o corpo (Freud, 1915, p. 148).

A pulsão não se dá em nível consciente ou inconsciente, sendo passível de ser conhecida apenas por seus representantes: os afetos e as ideias. Nesse sentido, a teoria das pulsões é marcadamente determinada por 
construtos teóricos cuja inteligibilidade é distinta das descrições empíricas, o que leva Freud a afirmá-la como a mitologia da Psicanálise (Garcia-Roza, 1985).

Primeiramente discutido como uma ampliação da sexualidade, em Três ensaios sobre a teoria da sexualidade (Freud, 1905), o conceito de pulsão foi "construído ao longo de toda a obra de Freud, que pode, de fato, ser estudada como uma longa elaboração não só desse conceito como das derivações que ele aportou em cada momento da evolução da teoria freudiana" (Jorge, 2010, p. 120). Esta é marcada pela proposição de duas teorias dualistas das pulsões, e a segunda virá a englobar e substituir a primeira.

Enunciado em 1910, o primeiro dualismo pulsional constitui-se pela oposição entre pulsões sexuais e pulsões de autoconservação ou do Eu (Roudinesco \& Plon, 1998). O estudo das psicoses, no entanto, gerou novas perguntas que impulsionaram modificações importantes. Freud (1923) afirma que

houve um progresso decisivo quando se passou à análise da dementia praecox [esquizofrenia] e de outras afecções psicóticas, começando assim a estudar o próprio Eu, até então conhecido apenas como instância repressora e opositora. Identificou-se como processo patogênico na demência o fato de a libido ser retirada dos objetos e introduzida no Eu. (p. 304)

A partir da obra Introdução ao narcisismo (Freud, 1914), o autor irá adotar nova distinção, subdividindo as pulsões sexuais em função de seu objeto. Ao propor que a libido pode também ser investida no $\mathrm{Eu}^{5}$ (Laplanche \& Pontalis, 2001), Freud cunhará os conceitos de libido do Eu e libido do objeto e definindo o primeiro como a libido que toma o próprio Eu como objeto e o segundo como o investimento em objetos externos ao Eu. A natureza distinta das pulsões será diluída, na medida em que a autoconservação nada mais seria do que amor a si mesmo, sendo toda pulsão em última instância sexual.

5 O termo Ich em alemão pode ser traduzido para Eu ou Ego. 
Como consequência, a distinção entre libido do eu e libido do objeto e o enfraquecimento do primeiro dualismo pulsional colocaram em duplo risco a teoria freudiana, aproximando-a cada vez mais da concepção monista de libido de Jung, com quem Freud havia rompido em 1913.

A substituição definitiva do primeiro dualismo pulsional ocorreu em 1920, com a publicação de Além do Princípio do Prazer, que marcou o início do último período da vida intelectual de Freud (Mezan, 2006). Reconhecendo que a Psicanálise havia se tornado uma disciplina autônoma, não dependendo mais exclusivamente de seu criador, ele pôde então voltar-se para temas que o interessavam, dando livre curso a sua tendência especulativa e colocando a agressividade em um lugar teórico de destaque, o que culminou em uma revisão da teoria.

Considerado um dos textos mais importantes da literatura psicanalítica, nesta obra Freud apresenta a segunda teoria das pulsões, inaugurando o que se denomina a sua "grande virada" teórica (Roudinesco \& Plon, 1998). Apresentando sete capítulos, Freud (1920) abre uma discussão sobre os limites da dominância do princípio do prazer, assinalando:

não é correto dizer que o princípio do prazer domina o curso dos processos psíquicos. Se assim fosse, a grande maioria de nossos processos mentais teria de ser acompanhada de prazer ou conduzir ao prazer, quando a experiência geral contradiz energeticamente essa ilação. O que pode então suceder é que haja na psique uma forte tendência ao princípio do prazer, à qual se opõem determinadas forças ou constelações de modo que o resultado final nem sempre corresponde à tendência ao prazer. (pp. 164 - 165)

Freud aponta fenômenos clínicos, entre os quais a entrada do princípio de realidade, que exige o adiamento da satisfação, as neuroses traumáticas, o jogo do Fort-da e a repetição na transferência, demonstrando que o princípio do prazer não é soberano. Reunindo esses fenômenos sobre a mesma égide (Jorge, 2010), o autor apresenta a hipótese da compulsão a repetição:

mais primordial, mais elementar, mais instintual [pulsional] do que o prinć́pio do prazer, por ela posto de lado. Se houver na psique uma tal compulsão à repetição, porém, então gostaríamos de saber algo sobre ela, a qual função 
corresponde, em que condições pode evidenciar-se, e que relação tem com o princípio do prazer, ao qual até agora, afinal, confiamos o domínio sobre o curso dos processos de excitação da vida mental (Freud, 1920, p. 184).

Neste sentido, Freud (1920) busca responder sobre a relação do caráter impulsivo com a compulsão à repetição, afirmando a pulsão como:

um impulso, presente em todo o organismo vivo, tendente à restauração de um estado anterior, que esse ser vivo teve que abandonar por influência de perturbadoras forças externas, uma espécie de elasticidade orgânica ou, se quiserem, a expressão da inércia da vida orgânica. (p. 202)

Por outro lado, estas considerações tornam possível afirmar que

seria contrário à natureza conservadora dos instintos que o objetivo da vida fosse um estado nunca antes alcançado. Terá de ser, isso sim, um velho estado inicial, que o vivente abandonou certa vez e ao qual ele se esforça por voltar, através de todos os rodeios de seu desenvolvimento. Se é lícito aceitarmos, como experiência que não tem exceção, que todo ser vivo morre por razões internas, retorna ao estado inorgânico, então só podemos dizer que o objetivo de toda a vida é a morte, e, retrospectivamente, que o inanimado existia antes do vivente (p. 204).

Freud define que as pulsões de autoconservação seriam parciais, acompanhando a vida até a morte. Por outro lado, se a dualidade pulsional é necessária na metapsicologia, as modificações apresentadas não podem deixar a pulsão sexual intacta, devendo ser entendida como a manifestação de um fenômeno profundo, cuja consideração sobre a reprodução em seu nível biológico virá respaldar (Mezan, 2006). Concebendo que as pulsões sexuais visam um prolongamento da vida, viabilizado por meio do encontro de células germinativas diferenciadas, Freud retorna ao campo da biologia. Citando diversos autores, como Weismann e Woodruff, ele pode afirmar seu novo dualismo pulsional: pulsões de vida e pulsões de morte (Freud,1920).

Voltando-se para o sadismo e o masoquismo, Freud (1920, p. 227) menciona as considerações de Spielrein sobre estes conceitos pela única vez na parte VI de Além do princípio do prazer, em nota de rodapé: “num 
trabalho substancial e pleno de ideias, embora não inteiramente claro para mim, Sabina Spielrein antecipou boa parte dessa especulação. Ela caracteriza o componente sádico do instinto sexual como destrutivo".

Encerrando o texto, Freud articula a pulsão de morte e a pulsão de vida, apontando que a primeira é silenciosa e só pode ser percebida na forma do sadismo e do masoquismo, associada à segunda (Garcia-Roza, 1990; Mezan, 2006).

Com o texto $O$ mal-estar na civilização (Freud, 1930), o caráter silencioso da pulsão de morte será contraposto à existência visível de uma tendência à agressividade no ser humano, sob forma de uma pulsão de agressão "especial e autônoma", como o "derivado e representante maior do instinto de morte, que encontramos ao lado de Eros e que partilha com ele o domínio do mundo" (Freud, 1930, p. 90). Desvinculando a destrutividade da sexualidade, este conceito tornou possível para Freud afirmar a "plena autonomia" da pulsão de morte, conferindo-lhe uma energia própria e distinta da libido (Garcia-Roza, 1990).

No texto freudiano, encontram-se apenas três referências a Sabina Spielrein, todas em nota de rodapé. Na literatura, a autora é amplamente citada por Jung (1911-1912/1956) na segunda parte de Símbolos da transformação, sendo mencionada em outras obras de sua autoria. Apesar de suas ideias inovadoras, a serem discutiras adiante, muito menos significativas são as referências a ela encontradas nos textos psicanalíticos; o trabalho de Spielrein é utilizado por Otto Gross (Checchia, 2016) e por Ferenczi (1926), no momento em que ambos se debruçaram sobre a questão da destruição.

Voltaremos agora às considerações sobre a obra de Sabina Spielrein, buscando evidenciar os caminhos de suas construções teóricas em torno da agressividade, destruição e pulsão de morte. O texto Sobre o conteúdo psicológico de um caso de esquizofrenia (Spielrein, 1911) foi publicado na terceira edição do Jahrbuch, considerada um marco da entrada da Psicanálise no campo da psicose (Cromberg, 2014). Citado por Freud (1911) em uma nota de $O$ Caso Schreber onde ele chama a atenção para a colaboração de Spielrein e Jung aos estudos nessa área, este é o texto spielreiniano que levantou questões fundamentais para seu ensaio sobre a pulsão de morte. $\mathrm{O}$ texto foi apresentado em meio aos conflitos que levaram a ruptura entre 
Freud e Jung e suas interpretações no campo inicial de recepção derivaram fortemente disto. Por vezes, tem-se a impressão de que ela foi vista apenas como uma mensageira de Jung (Cromberg, 2014).

Objetivando "estudar um caso de demência paranoide [...], movida apenas pela intenção de obter uma visão mais profunda dos processos psíquicos dessa doente" (Spielrein, 1911, p. 129), Spielrein discute a esquizofrenia, em um momento onde a questão da morte e da destruição começavam a surgir em sua clínica.

Sinalizando a insuficiência da teoria psicanalítica para a psicose, Spielrein (1911) afirma que "com uma doente tão dissociada [...] uma análise profunda é simplesmente impossível com os nossos recursos atuais" (p. 212). Dessa forma, as questões suscitadas por seu atendimento a levaram a tematizar a pulsão de morte. Tornando a esquizofrenia, além da neurose, o paradigma clínico de suas invenções, a autora conclui seu texto abrindo o campo para problematizar a morte e a sexualidade:

gostaria de ressaltar a enorme importância da "representação pelo oposto", descoberta por Freud para o surgimento das imagens da demência. Um caso especialmente importante é a representação do ato sexual pela simbólica da morte. A origem dessa representação está, a meu ver, na essência do próprio ato sexual, ou mais exatamente, nos dois componentes antagonistas da sexualidade (Spielrein, 1911, p. 216).

Junto ao grupo de discípulos de Freud que na segunda década do século XX buscaram alternativas conceituais para o primeiro dualismo pulsional (Cromberg, 2014), Spielrein (1912) introduz o conceito de pulsão de morte em seu texto $A$ destruição como origem do devir, escrito entre 1909 e 1912, com 49 páginas, onde procura responder:

Por que essa tão poderosa pulsão, a pulsão ${ }^{6}$ de procriação, esconde, ao lado dos sentimentos positivos que são esperados a priori, também outros negativos como angústia, aversão, os quais na verdade precisam ser superados para que possamos chegar ao ato positivo? (p. 229).

6 Spielrein, diferentemente de Freud, usa o termo Instinkt quando se refere a substantivos compostos como instinto de morte (Todesinstinkt) e instinto sexual (Sexualinstinkt), o termo Trieb quando se refere a pulsão de autoconservação (Selbsterhaltungstrieb), a pulsão de conservação da espécie (Arterhaltungstrieb) e a pulsão de procriação (Fortpflanzungstrieb), 
Utilizando a biologia e destacando efeitos do organismo biológicos sobre o psiquismo, Spielrein sustenta que há intenção criativa na destruição, que o ciclo de vida-reprodução-morte tem repercussões psíquicas na medida em que para se criar o novo deve-se destruir o antigo, o que gera conflito. Afirma que no ato sexual precipitam-se os incessantes processos de destruição e reconstrução (Cromberg, 2014), ilustrando os movimentos de vida e morte na natureza, tanto em seres vivos unicelulares quanto naqueles de organização elevada.

Em seguida, a autora parte da concepção de que no inconsciente não há temporalidade ou discriminação entre opostos, e cria um conceito que, na visão de Cromberg (2014), faz ressonância com a ideia freudiana de compulsão à repetição: Spielrein (1912) pressupõe a existência de uma tendência de retorno ao indiferenciado, onde "cada partícula do nosso ser deseja voltar a se transformar em sua fonte original, a partir da qual então o novo devir volta a emergir" (p. 235).

A autora "começa a [sua] decidida contribuição singular" (Cromberg, 2014, p. 302) ao perguntar:

afinal, não existem forças pulsionais em nós que colocam nosso conteúdo psíquico em movimento sem se preocupar com o bem estar e o sofrimento do Eu? Será que as pulsões básicas e conhecidas, a pulsão de autoconservação e de conservação da espécie, também significam para toda a vida psíquica aquilo que significam para a vida do Eu, ou seja, a fonte do prazer e do desprazer? (Spielrein, 1912, pp. 236-237).

Questionando se possuímos impulsos poderosos independentes do princípio do prazer, e se as pulsões de autoconservação e de conservação da espécie são a origem do prazer e do desprazer, tanto para a vida psíquica quanto para o Eu (Caropreso, 2016; Cromberg, 2014), Spielrein (1912) defende que

termo utilizado pela autora para se referir a pulsão sexual e a pulsão de conservação da espécie, e o termo Drang quando se refere ao impulso de destruição (Destruktionsdran) (Caropreso, 2016; Cromberg, 2014). 
a psique do $\mathrm{Eu}^{7}$, inclusive a inconsciente, é guiada por moções que se encontram ainda mais profundas e não se ocupam nem um pouco com nossas reações emocionais às demandas impostas por elas. O prazer é simplesmente a reação afirmativa do Eu a essas demandas originárias do âmago e nós podemos ter prazer diretamente a partir do desprazer e prazer pela dor, a qual, tomada em si mesma, é fortemente carregada de desprazer, pois a dor corresponde a um prejuízo do indivíduo, contra o qual nosso instinto de autoconservação se opõe. Portanto, em nosso âmago há algo que, por mais paradoxal que isso possa soar a priori, busca esse autoprejuízo, uma vez que o Eu reage a ele com prazer. $O$ desejo de autoprejuízo, o regozijo pela dor, é, no entanto, completamente incompreensível se considerarmos apenas a vida do Eu, a qual só quer ter prazer. (p. 237, grifo nosso)

Considerando a possibilidade do aparelho psíquico guiar-se também pela busca do desprazer, autoprejuízo e dor, Spielrein formula, de acordo com a leitura de Cromberg (2014), a hipótese do sofrimento masoquista, aproximando-se do que Freud denominará masoquismo originário e, ao mesmo tempo, ressaltando os efeitos traumáticos dos excessos pulsionais sobre o psiquismo.

Tendo como base a existência de um Eu que visa a inércia de seus primórdios infantis e se deixa destruir para renascer modificado, Spielrein (1912) afirma que a destruição é a origem do devir, na medida que há no Eu uma possibilidade de se recriar e de renovar suas representações. Para a autora, coexistem no aparelho psíquico duas tendências, uma de transformação e outra que deseja perseverar, processos cuja força motriz é a pulsão de morte.

Discorrendo sobre a existência de uma fusão entre destrutividade e amor, Spielrein (1912) conclui que:

Essa teoria é muito adequada para explicar porque não enxergamos o instinto de morte no instinto sexual. Sob circunstâncias normais, as representações do devir devem predominar um pouco, mesmo porque o devir é resultado da destruição, é determinado pela destruição. No

7 Spielrein entende de maneira inédita que o aparelho psíquico se divide entre o "Eu" (psique do Eu) e o "Nós" (psique da espécie) e concebe que a psique do Eu (Ichpsyque) é regida pela pulsão de autoconservação e a psique da espécie (Artpsyche) pela pulsão da conservação da espécie (Cromberg, 2014). 
entanto, é muito mais fácil pensar nos resultados finais do que sempre buscar a causa. Mas não é preciso muito para que as representações de destruição predominem, principalmente em crianças ou pessoas emotivas. Na neurose, o componente da destruição predomina e se expressa em todos os sintomas de resistência à vida e ao destino natural. (pp. 259-260, grifo nosso)

A autora propõe que os sentimentos negativos, como angústia e aversão, que na neurose aparecem juntamente com a pulsão sexual, devem-se à vitória do componente destrutivo. Se, de acordo com Spielrein (1912) "na própria vida está a fonte da morte, assim como na morte está a vida" (p. 272), a destrutividade e a morte são inerentes à sexualidade e à psique. Os sintomas neuróticos, por sua vez, surgem em função de uma paralisação da vida e da sexualidade que objetiva evitar a morte, mas que não consegue, na medida que esta se instala no centro da própria sintomatologia (Cromberg, 2014).

Ocultando o instinto de morte na pulsão sexual, dado que a vida é efeito da morte (Cromberg, 2014), a autora estreita as relações entre sexualidade e destrutividade, sinalizando a existência de uma tendência do aparelho psíquico que vai além do princípio do prazer. Entretanto, diferentemente das concepções freudianas, de acordo com Spielrein:

a destruição é, portanto, a causa do devir; o antigo deve ser destruído para que o novo possa surgir. É por isso que não existe o conceito absoluto de morte, porque a morte para o que é antigo significa a vida para o que é novo. É verdadeiro que a morte em si é aterrorizante, mas a serviço do instinto sexual ela é também benéfica (Nunberg \& Federn, 1979, p. 321, tradução nossa).

Não examinaremos aqui, mas apontamos que o texto também apresenta questões sobre as relações entre Psicanálise e linguagem, sobre o amor, sofrimento, sublimação e arte (Spielrein dialoga bastante também com Nietzsche), que marcarão fortes interesses posteriores da autora.

Cabe abordar agora as repercussões de suas ideias na Psicanálise, a partir da apresentação parcial de $A$ destruição como origem do devir na Sociedade Psicanalítica de Viena em 29 de novembro de 1911. Registrada nas Atas da Sociedade Psicanalítica de Viena (Nunberg \& Federn, 1979), esta conferência, intitulada Sobre a transformação, contou com a presença de 
dezoito homens e uma mulher e foi seguida por debate. Neste documento, chama a atenção a nota de rodapé da primeira página, que introduz Spielrein como oradora: "A Dra. Spielrein foi minha colega na faculdade de medicina. Ela foi fortemente influenciada por Jung. Durante seus estudos, ela viveu um episódio psicótico" (Nunberg \& Federn, 1979, p. 319, tradução nossa).

Na discussão foram abordadas as relações entre nascimento e morte, o papel da mitologia e da biologia nas construções psicanalíticas e as aproximações das propostas de Spielrein e Jung. Entre as críticas, destacam-se os questionamentos acerca da falta de distinções entre a Psicanálise e a biologia e entre a vida individual e universal. Este último ponto é mencionado por Freud (1913, p. 355) que cita Spielrein, Abraham e Jung enquanto colaboradores na ampliação do interesse da Psicanálise com 'a tese' segundo a qual 'a ontogenia é repetição da filogenia”'.

As críticas foram rebatidas por Spielrein, que afirmou que a omissão de um capítulo de seu texto dificultou o entendimento. A despeito disto, parte dos presentes, como Sachs, Tausk e Rosenstein, consideraram interessantes as teorizações sobre a relação entre a sexualidade e a destruição e entre o nascimento e a morte. Freud teceu um longo comentário ao trabalho, aproveitando para criticar a utilização que Jung vinha fazendo do material mitológico. Ele considerou inadequado o uso da biologia, que teria subordinado a Psicanálise (McGuire, 1993; Nunberg \& Federn, 1979). De forma geral, as ideias de Sabrina foram provavelmente ofuscadas pelos conflitos políticos em torno da relação Freud-Jung.

\section{CONCLUSÃO: SPIELREIN E FREUD, UMA CONVERSA PRODUTIVA}

Após nosso breve percurso, podemos afirmar que, a despeito das fortes marcas junguianas no texto de Spielrein, ela firmou-se ao lado dos pilares teóricos de Freud, antecipando temas que serão trabalhados por ele a partir de 1920.

Sabina permaneceu sempre vinculada à Sociedade Psicanalítica, trabalhando, trocando correspondências com Freud, presente nos eventos importantes, como o Congresso de Haia, participando do movimento 
institucional da Psicanálise quando colabora para sua implementação na União Soviética e exercendo mesmo na ilegalidade, quando fora proibida pelo stalinismo.

Temos o fato de que o stalinismo afastou Spielrein, impedindo-a de se comunicar com os demais psicanalistas. Este foi um efeito também da Segunda Guerra Mundial e do nazismo, que obrigaram parte dos membros da Sociedade a se refugiarem, com consequências políticas e institucionais, em meio às quais provavelmente a figura de Spielrein perdeu-se, incomunicável na União Soviética (Cromberg, 2008).

Quanto a pulsão de morte, é importante recordar que após a publicação de A destruição como origem do devir (Spielrein, 1912), Spielrein permaneceu ao lado de Freud, encontrando-se ainda muito próxima do movimento psicanalítico em 1920, quando Além do princípio do prazer foi publicado. Freud sempre apoiou a carreira dela, não tendo motivos manifestos para não referenciar sua autoria.

Outro ponto a ressaltar diz respeito à trajetória que culminou na proposição do conceito de pulsão de morte para ambos os autores. A dificuldade de responder às questões sobre a psicose (esquizofrenia) - seja em Sobre o conteúdo psicológico de um caso de esquizofrenia (Spielrein, 1911) ou em O Caso Schreber (Freud, 1911) - pode ser apontada como um dos motivos que os levou a esta formulação. Entretanto, é necessário ressaltar que as produções e modificações teórico-clínicas de Spielrein e Freud não podem ser reduzidas a uma única questão disparadora. A revisão da teoria pulsional freudiana, por exemplo, reflete inúmero motivos anteriores à obra e a compreensão da psicose foi apenas um destes. Ainda assim, vemos que as complexidades clínicas conduziram ambos autores a questionar a leitura psicanalítica do prazer e, por consequência, do desprazer e da agressividade.

Além disso, pensemos nas relações entre a Psicanálise e a biologia. Vimos que Freud criticara Spielrein em 1911 por procurar referências, subordinando a Psicanálise a pressupostos biológicos. Por outro lado, vemos Freud mencionar o biólogo Weissmann e tratar de organismos unicelulares em Além do princípio do prazer (Freud, 1920), repetindo aquilo que criticara na obra de Spielrein. A formulação freudiana de pulsão de morte se ancorará na biologia em seus primeiros tempos, desvencilhando-se desta 
com O mal-estar na civilização (Freud, 1930). Temos aqui um ponto de convergência. Talvez porque a morte é também a morte do corpo, uma condição inerente a todos os seres vivo, a biologia tornou-se importante para os autores em suas proposições sobre a tendência para a morte ou se tratava somente de uma dificuldade de ancorar outras referências para esta reflexão? Para responder a isto, precisaríamos investigar mais profundamente a presença da biologia nas obras dos dois autores.

Ainda sobre semelhanças, ambos apresentam acepções bastante próximas sobre o sadismo e o masoquismo, e Freud refere-se às proposições de Spielrein sobre o masoquismo originário, e neste ponto convergem. Sabina afirma a possibilidade de se obter prazer pelo desprazer ou pela dor, menciona o desejo pelo autoprejuízo, e assim antecipa a hipótese freudiana de que há algo além do princípio do prazer, apontando para a repetição mortífera. Ambos problematizam os efeitos traumáticos dos excessos pulsionais.

Quanto à definição da pulsão de morte, Freud caracteriza-a como uma pulsão que objetiva a redução absoluta das tensões, conduzindo o ser vivo de volta ao estado inorgânico pela via do desligamento, da dissolução das conexões e da destruição. Já em Spielrein, a pulsão de morte está oculta na pulsão sexual e, a despeito de visar a destruição, ela não objetiva a aniquilação da vida ou a eliminação total da estimulação, mas sim a transformação, morte para o antigo e vida para o que vai surgir.

Nele temos uma teoria da destruição, do aniquilamento das tensões, enquanto nela vemos uma teoria da transformação, sempre no campo da intersubjetividade. Uma diferença profunda entre Freud e Spielrein, um ponto onde eles não conversam. Mas será que não poderiam? Se pensarmos que a "pulsão de morte é renovadora [...] no sentido de [...] recusar a permanência do 'mesmo', de provocar na natureza e na cultura a emergência de novas formas" (Garcia-Roza, 1990, pp. 134-135), o que será proposto em O Mal-estar na civilização (Freud, 1930), talvez possamos cogitar que a destruição seja a origem do devir. Considerando que, para Freud, é da atuação conjunta das pulsões de vida e de morte que surgem os fenômenos da vida, deve-se questionar se nesse ponto ele não se aproxima da teoria spielreiniana. 
Assim, remetemos o leitor à obra desta notória mulher, para que faça suas próprias análises, como esboçamos aqui. De forma geral, interessa-nos ressaltar as colaborações e originalidades da relevante autora, sem reduzi-la ao texto freudiano. Por outro lado, não se trata também de negar a genialidade de Freud, mas de realizar uma tentativa de apontar para as complexidades envolvidas nas produções teórico-clínicas da Psicanálise. Assim, conhecer o campo psicanalítico em torno de Freud permite-nos sem dúvida maior aprofundamento na compreensão de suas proposições e, ao mesmo tempo, confere maior riqueza conceitual e clínica à Psicanálise, desde sua origem.

Por fim, a vida e obra de Sabina Spielrein lançam luz para a importância de se reconhecer a autoria das mulheres que desde o início compuseram o movimento psicanalítico. Podemos relembrar que este teve um importante papel para as mulheres do século XX, não somente por via da escuta das pacientes histéricas, mas também porque possibilitou um campo de trabalho para aquelas que almejavam a ocupação do espaço publico. Graças também a elas, a Psicanálise permanece fortemente ativa e pode revisitar-se continuamente.

\section{REFERÊNCIAS}

Alonso, S. L. (2014). Prefácio - O Processo de construção de uma história. In R. U. Cromberg (Org.). Sabina Spielrein: uma pioneira da psicanálise (Vol. 1, pp. 9-19). São Paulo: Livros da Matriz.

Brome, V. (1967). Freud and his early circle. Nova Iorque: Apollo Editions. Caropreso, F. (2016) O instinto de morte segundo Sabina Spielrein. Psicologia USP, 27(3), 414-419.

Carotenuto, A. (1984). Diário de uma secreta assimetria. Rio de Janeiro: Paz e Terra.

Checchia, M. (2016). Combate a vontade de potência. São Paulo: Annablume.

Cromberg, R. U. (2008) O amor que ousa dizer seu nome: Sabina Spielrein - Pioneira da Psicanálise. (Tese de Doutorado). Universidade de São Paulo, São Paulo. 
Cromberg, R. U. (Org.), (2014). Sabina Spielrein: uma pioneira da psicanálise (Vol. 1). São Paulo: Livros da Matriz.

Cromberg, R. U. (2017). Psicanálise na Rússia. In P. S. Souza Jr. (Org.), A psicanálise e os lestes (Vol. 1, pp. 91-142). São Paulo: Annablume.

Cronenberg, D. (Diretor) \& Thomas, J. (Produtor). (2011). Um método perigoso [DVD]. Canadá: Lago Filme.

Endo, P. (2015). O frescor e a inventividade dos pioneiros da psicanálise: Sabina Spielrein. Trivium - Estudos Interdisciplinares, 7(2), 331-336.

Ferenczi, S. (1926) O problema da afirmação do desprazer. In S. Ferenczi, Psicanálise III (A. Cabral, Trad.) (pp. 393-404). São Paulo: Martins Fontes.

Figueiredo, L. C. (1999). Palavras cruzadas entre Freud e Ferenczi. São Paulo: Escuta.

Franza, R. (Diretor) \& Ferri, E. (Produtor). (2002). Jornada da alma [DVD]. Itália: Medusa Produções.

Freud, S. (1905). Três ensaios sobre a teoria da sexualidade. In S. Freud, Freud - Obras Completas (P. C. de Souza, Trad.) (Vol. 6, pp. 13-172). São Paulo: Companhia das Letras.

Freud, S. (1911). Observações psicanalíticas sobre um caso de paranoia [dementia paranoides] relatado em autobiografia ("O Caso Schreber", 1911). In S. Freud, Freud - Obras Completas (P. C. de Souza, Trad.) (Vol. 10, pp. 13-107). São Paulo: Companhia das Letras.

Freud, S. (1913). O interesse da psicanálise. In S. Freud, Freud - Obras Completas (P. C. de Souza, Trad.) (Vol. 11, pp. 328-363). São Paulo: Companhia das Letras.

Freud, S. (1914). Introdução ao narcisismo. In S. Freud, Freud - Obras Completas (P. C. de Souza, Trad.) (Vol. 12, pp. 13-50). São Paulo: Companhia das Letras.

Freud, S. (1915). O instinto e seus destinos. In S. Freud, Freud - Obras Completas (P. C. de Souza, Trad.) (Vol. 12, pp. 51-81). São Paulo: Companhia das Letras. 
Freud, S. (1920). Além do princípio do prazer. In S. Freud, Freud - Obras Completas (P. C. de Souza, Trad.) (Vol. 14, pp. 161-239). São Paulo: Companhia das Letras.

Freud, S. (1923). "Psicanálise" e "Teoria da Libido". In S. Freud, Freud Obras Completas (P. C. de Souza, Trad.) (Vol. 15, pp. 273-308). São Paulo: Companhia das Letras.

Freud, S. (1930). O mal-estar na civilização. In S. Freud, Freud - Obras Completas (P. C. de Souza, Trad.) (Vol. 18, pp. 13-122). São Paulo: Companhia das Letras.

Freud, S. (1939). Esboço de Psicanálise. In S. Freud, Edição Standard Brasileira das Obras Psicológicas Completas de Sigmund Freud (Vol. 23, pp. 151-221). Rio de Janeiro: Imago.

Garcia-Roza, L. A. (1985). Freud e o Inconsciente (2. Ed.). Rio de Janeiro: Jorge Zahar.

Garcia-Roza, L. A. (1990). O Mal radical em Freud (4. Ed.). Rio de Janeiro: Jorge Zahar.

Gay, P. (2012). Freud: uma vida para nosso tempo. (2. Ed.). São Paulo: Companhia das Letras.

Jorge, M. A. C. (2010) Fundamentos da psicanálise de Freud a Lacan (Vol. 2). Rio de Janeiro: Jorge Zahar.

Jung, C. G. (1911-1912/1956). Símbolos da transformação. In C. G. Jung, Obra Completa de C.G. Jung (E. Stern, Trad.), (7. Ed., Vol. 5). Petrópolis: Vozes.

Jung, C. G. (1942). Psicologia do inconsciente. In C. G. Jung, Obra Completa de C.G. Jung (M. L. Appy, Trad.), (23. Ed., Vol. 7/1). Petrópolis: Vozes.

Laplanche, J. \& Pontalis, J. B. (2001) Vocabulário da psicanálise (4. Ed.). São Paulo: Martins Fontes.

Mcguire, W. (Org.). (1993). A correspondência completa de Sigmund Freud e Carl G. Jung (L. Fróes, \& E. A. M. Souza, Trad.). Rio de Janeiro: Imago.

Mezan, R. (2006). Freud: a trama dos conceitos. São Paulo: Perspectiva. 
Nunberg H. \& Federn E. (Org.) (1979) Les premiers psychanalystes: Minutes de la Société psychanalytique de Vienne (Vol. 3). Paris: Gallimard.

Richebächer, S. (2012) Sabina Spielrein: de Jung a Freud. Rio de Janeiro: Civilização Brasileira.

Robert, M. (1966). The Psychoanalytic Revolution. Nova Iorque: Harcourt. Rodrigue, E. (1995) Sigmund Freud, o século da Psicanalise: 1895-1995. São Paulo: Escuta.

Roudinesco, E. (2009). As Primeiras mulheres psicanalistas. In M. A. C. Jorge (Org.), Em defesa da psicanálise: ensaios e entrevistas (pp. 86-91). Rio de Janeiro: Jorge Zahar.

Roudinesco, E. (2016) Sigmund Freud na sua época e em nosso tempo. Rio de Janeiro: Jorge Zahar.

Roudinesco, E. \& Plon, M. (1998). Dicionário de Psicanálise. Rio de Janeiro: Jorge Zahar.

Spielrein, S. (1909-1912/1984) Diário de Sabina Spielrein. In A. Carotenuto, Diário de uma secreta simetria (pp. 191-231. Rio de Janeiro: Paz e Terra.

Spielrein, S. (1911) Sobre o conteúdo psicológico de um caso de esquizofrenia, (R. D. Mundt, Trad.). In R. U. Cromberg (Org.), Sabina Spielrein: uma pioneira da psicanálise (Vol. 1, pp. 127-216). São Paulo: Livros da Matriz.

Spielrein, S. (1912) A destruição como origem do devir, (R. D. Mundt, Trad.). In R. U. Cromberg (Org.), Sabina Spielrein: uma pioneira da psicanálise (Vol. 1, pp. 127-216). São Paulo: Livros da Matriz.

Widlöcher, D. (1988) Prólogo. In A. Green (Org.), Pulsão de Morte (pp. 7-11). São Paulo: Escuta. 